\title{
Offspring size and maternal environments mediate the early juvenile performance of two congeneric whelks
}

\author{
Sergio A. Carrasco ${ }^{1, *}$, Nicole E. Phillips ${ }^{1}$, Alejandro Pérez-Matus ${ }^{2}$ \\ ${ }^{1}$ School of Biological Sciences and Coastal Ecology Laboratory, Victoria University of Wellington, Wellington 6140, \\ New Zealand \\ ${ }^{2}$ Laboratorio de Ecología Marina, Facultad de Ciencias del Mar y de Recursos Naturales, Universidad de Valparaíso, \\ Casilla 5080, Avenida Borgoño 16344, Viña del Mar, Chile
}

\begin{abstract}
Offspring size variation can have pervasive ecological and evolutionary implications for both offspring and mother, affecting an organism's performance throughout its life. Using 2 marine intertidal whelk species Cominella virgata and C. maculosa as model organisms, we examined how different maternal environments and contrasting hatchling size influence juvenile performance. The average size of field-collected hatchlings greatly differed between the species and at different scales of variation (i.e. among sites). Species-specific differences in hatching size were reflected in juvenile performance. Overall, $C$. virgata with larger hatchlings $(\sim 3 \mathrm{~mm})$, exhibited faster growth rates and higher survival than the smaller $C$. maculosa $(\sim 1.5 \mathrm{~mm})$. Desiccation treatment did not affect the performance of fed juveniles; however, large hatchlings had higher growth rates than small conspecifics for both species. Starved hatchlings of both species performed more poorly than fed ones; however, species-specific and size differences were less significant for the evaluated traits, suggesting a non-size-related allocation of resources and similar resource utilization during starvation conditions (i.e. within species). As has been described for many taxa, large offspring often perform better than small conspecifics; however, because this performance is likely context-dependent, understanding the importance of different scales of variation is crucial for determining when variation in size is an advantage or a disadvantage in terms of an organism's performance.
\end{abstract}

KEY WORDS: Progeny size $\cdot$ Reproductive strategies $\cdot$ Environmental variation $\cdot$ Phenotypic plasticity $\cdot$ Offspring size-fitness $\cdot$ Cominella

\section{INTRODUCTION}

Offspring size is a key trait for most organisms, influencing an individual's subsequent performance and having direct consequences in fitness for both the offspring and mother. For a range of taxa across a variety of habitats, individuals that start juvenile life with a large size often perform better than smaller conspecifics. This pattern has been shown for gastropods (Spight 1976, Gosselin 1997, Moran \& Emlet 2001), mussels (Phillips 2002), barnacles (Thiyagara- jan et al. 2003), ascidians (Marshall et al. 2003, 2006), beetles (Fox 2000, Clark et al. 2011), isopods (Tsai \& Dai 2001), spiders (Walker et al. 2003), fish (Green \& McCormick 2005, Fisher et al. 2007), and birds (Krist 2011). Therefore, intraspecific variation in offspring size is of fundamental ecological and evolutionary importance (Marshall \& Keough 2008). Offspring size often varies spatially (i.e. among and within populations, clutches, or siblings) and temporally (Bernardo 1996). Several explanations have been proposed for these scales of variation, but they are often attributed 
to either non-adaptive stochastic variation in provisioning or to a maternal bet-hedging strategy in unpredictable environments (see Kamel et al. 2010).

The ability of mothers to anticipate the environment that their offspring will experience may therefore mediate variation in offspring size. When mothers are able to predict their offspring's environment, the expectation is that plasticity in mean offspring size will be favored ('anticipatory' maternal effects; Marshall \& Uller 2007). Conversely, when mothers are unable to predict the environment, the expected outcome is that increases in the variation of offspring size will ensure that some offspring will be optimal for the environment (Crean \& Marshall 2009). Regardless of the strategy, the division of finite reproductive resources should ultimately result in an optimal equilibrium between the offspring fitness and the maximization of the parental fitness, and therefore, simple models have typically suggested that as the relationship between progeny size and progeny fitness changes, the optimal size of progeny is also expected to change as environmental conditions vary (Fox 2000, Walker et al. 2003). Examples provided by Allen et al. (2008) for marine invertebrates suggest that harsh environmental conditions have a steeper offspring size-fitness relationship than more benign conditions. Hence, an evolutionary response would result in larger offspring sizes in adverse conditions (e.g. highly competitive environments, high predation pressure, or high wave exposure), whereas offspring size would be less important in more favorable environments.

Spight (1976) suggested predation as a component of environmental severity for early juvenile benthic invertebrates. Food limitation, especially in the beginning of benthic life, is also a critical factor that can influence the growth and survival of juveniles (Gallardo et al. 2004b, Moran \& Manahan 2004). For juvenile intertidal organisms, however, vulnerability also includes other physical factors that do not occur in most terrestrial and freshwater habitats, such as wave exposure, desiccation, and temperature fluctuations, which often result in mortality and affect the distributional limits of the species (Gosselin \& Chia 1995a,b, Helmuth et al. 2002).

Several studies of invertebrates with larval stages have shown that larger sizes are often correlated with better performance in terms of feeding rate, duration of planktonic period, settlement rate, growth rate, and survival (Phillips 2002, Marshall et al. 2003, Marshall \& Keough 2004, 2009). In contrast, for direct developers that lack a planktonic larval stage, maternal provisioning to the embryos at the time of spawning is the primary source of nutrition until the offspring enter juvenile life (Spight 1976, Rivest 1983). This characteristic makes direct-developing invertebrates an interesting model system to evaluate how maternal environments and initial maternal-derived resources affect offspring traits (e.g. size, growth rate, and overall survival) and to determine the scales of variation at which these maternal effects are evident and comparable within or among populations. To date, few studies have examined this system; however, they have found consistent relationships between hatchling size and performance (e.g. larger hatchlings showing better growth and survival than small conspecifics; Moran \& Emlet 2001), hatchling size and maternal habitat (e.g. smaller hatchling sizes from more protected habitats; Lloyd \& Gosselin 2007), and maternal resources and offspring performance (e.g. higher growth of juveniles from mothers in better food conditions; van der Sman et al. 2009).

Because maternal food resources can ultimately limit the energy available for allocation, variation in food availability can be an important factor influencing the amount of energy available for reproduction (Du 2006). One coastal region where resources vary between 2 neighboring locations is at the southern end of the North Island of New Zealand, first described by Morton \& Miller (1968), i.e. the semienclosed and nutrient-rich Wellington Harbor vs. the exposed and low productivity Wellington southern coast. Compared to the nearby southern coast, Wellington Harbour has denser and more speciesrich intertidal communities with greater recruitment rates of fish and invertebrates (Phillips \& Hutchison 2008, Shima \& Swearer 2009, Demello \& Phillips 2011), higher standing stocks of phytoplankton and concentrations of particulates (Gardner 2000, Helson et al. 2007), higher quality and faster growing larval reef fish (Shima \& Swearer 2009, 2010, Swearer \& Shima 2010), and higher growth rates for several species of whelks (N. Phillips unpubl. data).

Here, we used sympatric direct-developing whelks with different reproductive strategies, using Cominella virgata (1 large hatchling per capsule) and C. maculosa (multiple small hatchlings per capsule) as models to examine how maternal environments influence the size and performance of juveniles. There were 2 major aims: (1) to examine variation in hatchling size within and among different $C$. virgata and $C$. maculosa populations and (2) to determine whether initial hatchling size mediates the performance of juveniles when exposed to different stressors (i.e. desiccation and starvation). We hypo- 
thesized that (1) hatchlings from different maternal environments will perform differently, i.e. hatchlings from productive maternal environments (i.e. Wellington Harbour) will perform better than hatchlings from less productive maternal conditions (i.e. the southern coast), and (2) the performance of hatchlings from the same maternal environment will be a function of size, with large individuals performing better than small conspecifics.

\section{MATERIALS AND METHODS}

\section{Study species and collections}

Cominella virgata and C. maculosa (Neogastropoda: Buccinidae) are common scavenging whelks found in pools, under stones, or in moist depressions in the low intertidal zone down to the sublittoral fringe and subtidally on rocky shores throughout New Zealand (Morton \& Miller 1968). Females of both species attach morphologically different egg capsules to rock surfaces. C. virgata encapsulates a single embryo per capsule ( 3 $\mathrm{mm}$ hatching size), while C. maculosa deposits $\sim 8$ embryos inside each capsule ( 1.5 mm hatching size), but all usually develop. Intra-capsular nutrition (e.g. nurse eggs) is absent in both species, and the embryos rely entirely on the initial maternal provisioning at the time of spawning. The egg laying period begins in midSeptember, and the development period lasts $~ 90 \mathrm{~d}$ (van der Sman 2007).

To evaluate the hatchling size and performance of Cominella virgata and C. maculosa in response to contrasting maternal environments, we collected groups of egg capsules (>20 capsules per group), in which hatching was imminent (i.e. fully developed snails were clearly visible inside the capsule), from 4 sites around the Wellington region of New Zealand $\left(41^{\circ} 17^{\prime} \mathrm{S}, 174^{\circ} 50^{\prime} \mathrm{E}\right)$ : 2 sites within Wellington Harbour, Point Howard (PH) and Point Halswell (PHS), and 2 sites on the Wellington southern coast, Moa Point (MP) and Te Raekaihau Point (TR). At each of these sites, 20 groups of egg capsules of $C$. virgata and 12 of C. maculosa were collected.

Egg capsule groups were collected during low tides in December 2008 (Cominella virgata) and December 2009 (C. maculosa) from intertidal pools, in crevices, or on the undersides of boulders. To ensure that each of them represented the reproductive output of a single female, the egg capsules were collected from different rocks within each sampling site. Groups of egg capsules were carefully detached from the rocks using a scalpel and then transported in seawater to the laboratory, where each of them was placed in a $500 \mathrm{ml}$ jar fitted with mesh sides $(500 \mu \mathrm{m}$ mesh) that allowed for water flow. The jars were half submerged in a large shallow tank supplied with constantly flowing fresh seawater at ambient temperature (mean $\pm \mathrm{SD})$ until hatching $\left(16.4 \pm 0.5^{\circ} \mathrm{C}\right.$ in 2008 and $15.7 \pm 0.7^{\circ} \mathrm{C}$ in 2009). Experiments were conducted at the National Institute of Water and Atmospheric Research (NIWA) and the Victoria University Coastal Ecology Laboratory (VUCEL).

\section{Hatchling size}

To quantify variation in hatchling size among the different Cominella virgata and C. maculosa populations, 20 haphazardly selected hatchlings from a subset of 5 of the groups of egg capsules collected per site ( $\mathrm{n}=100$ hatchlings per site; except $C$. maculosa from TR with $\mathrm{n}=99$ ) were measured from the apex of the shell to the end of siphonal notch (shell length [SL], mm) using a dissecting microscope equipped with an ocular micrometer at 20 and 40× magnification, respectively. The differences in hatchling size were evaluated in the present study between locations (Harbour and South Coast) and among sites (PH, PHS, MP, and TR). Due to difficulties in accurately identifying individual clutches in the field, this source of variability was not included in the model. We used nested mixed-model analyses of variance (ANOVA) for each species to examine whether hatchling size varied by location (fixed factor) with sites nested within locations (random factor). When the mixed models failed to find significant differences between locations, but there was substantial variation among sites, we further examined differences among sites with 1-way ANOVAs.

\section{Size-dependent performance as a function of the maternal environment and experimental conditions}

We evaluated the performance of different-sized juveniles with 2 manipulative experiments: (1) desiccation and (2) starvation (Cominella virgata: December 2008 to February 2009; C. maculosa: December 2009 to February 2010). Hatchlings (48 h after hatch) from the 4 sites ( $\mathrm{PH}, \mathrm{PHS}, \mathrm{MP}$, and TR) were placed in $500 \mathrm{ml}$ jars as described in 'Study species and collection'. For each site and species, snails above the mean length (i.e. the average size of 100 individuals) were considered large (L), and those below the mean 
were considered small (S). Within each size class, hatchlings were haphazardly assigned to each container.

For both species, the desiccation experiments were conducted using 200 hatchlings per site: 100 always submerged in seawater (control) and 100 in a desiccation treatment. For each treatment, 5 replicate containers of each size class ( $\mathrm{L}$ and $\mathrm{S}$ ) were used with 10 hatchlings each. In the region of collection, adults of these species probably experience tidal emersion 3 to 5 times a week, for 1 to $3 \mathrm{~h}$ per low tide, although the duration and amplitude of low tides varies considerably depending on the tidal cycle, wind swell, and other factors. Further, juveniles are almost exclusively found at the sublittoral fringe and in moist, shaded habitats, such as in crevices or under boulders (N. Phillips pers. obs.), and thus likely have a shorter aerial exposure at low tide compared with adults. Therefore, the desiccation treatment for hatchlings was consistently simulated for $1.5 \mathrm{~h}$ during mid-day 3 times per week by transfering the containers from the seawater to a dry tray. Food was provided once a week using the adductor muscle $\left(1 \mathrm{~cm}^{2}\right)$ of the mussel Perna canaliculus (after van der Sman et al. 2009).

In the starvation treatment (no food provided), we used 60 hatchlings per species and site, with 30 of each size class ( $\mathrm{L}$ and $\mathrm{S}$ ) distributed to 3 replicate containers with 10 snails each. Given the limited number of hatchlings available for this experiment, the performance of large and small starved individuals from each site was contrasted with those in control conditions from the first experiment (i.e. fed and submerged in water).

In desiccation and starvation experiments, SL (mm) were measured weekly using a dissecting microscope at $20 \times$ or $40 \times$ magnification (for Cominella virgata and C. maculosa, respectively), allowing us to estimate the daily growth rate $\left(\mathrm{GR}, \mathrm{mm} \mathrm{d}^{-1}\right)$. Due to the logistics of handling and tagging so many individuals, we were unable to follow individual hatchlings during the experiments; therefore, growth rates were calculated based on a per container average (after van der Sman et al. 2009).

To compare the variation in GR among sites, treatments, size classes, and their interactions, we used either a 3-way ANOVA (desiccation experiment) or a 2-way ANOVA (starvation experiment), followed by a Tukey's HSD post hoc test when appropriate. Homogeneity of variance was tested using Cochran's $C$ test, and the data did not require transformation to meet ANOVA assumptions.

In both experiments, hatchling survival was evaluated weekly, and dead individuals were removed until the survival in any of the replicates had decreased to 2 individuals. To determine if survival under experimental conditions was significantly different from that of hatchlings under control conditions, we used a generalized linear model (GLM; Crawley 2007) because our response variable was based upon counts (number of hatchlings) that had unequal variances and non-normally distributed errors. We conducted 2 separate analyses, one consisting of orthogonal contrast between the survival of large and small individuals from each site against the hatchlings in control conditions, and another analysis comparing the survival of hatchlings under desiccation or starvation from the 4 study sites against hatchlings in control conditions. For these GLMs, we specified a binomial error distribution and a logit link function (Crawley 2007). The data were not overdispersed (i.e. desiccation experiment: Cominella virgata, residual deviance $=29.9$ over $555 \mathrm{df}$ and C. maculosa, residual deviance $=135.4$ over $288 \mathrm{df}_{\text {; }}$ starvation experiment: C. virgata: residual deviance $=23.8$ over $112 \mathrm{df}$ and $C$. maculosa: residual deviance $=29.9$ over $43 \mathrm{df}$ ). Statistical analyses were performed using the R 2.12 (R Development Core Team 2010) and JMP 9 (SAS Institute 1989-2007) software packages.

\section{RESULTS}

\section{Hatchling size}

Consistent with other reports, Cominella virgata hatchlings (SL: $2.67 \pm 0.03 \mathrm{~mm}$; always mean $\pm \mathrm{SE}$ ), were almost twice as large as $C$. maculosa hatchlings (SL: $1.51 \pm 0.02$ mm; Fig. 1).

Cominella virgata hatchling size did not differ between the 2 locations $\left(F_{1,2}=0.140, \mathrm{p}=0.744\right)$, with hatchlings from the South Coast and Harbour exhibiting similar SL $(2.70 \pm 0.05 \mathrm{~mm}$ vs. $2.63 \pm 0.05 \mathrm{~mm}$, respectively). The mixed-model ANOVA with sites as random factor further revealed that a large proportion of the variance in hatchling size $(32 \%)$ occurred among sites, with the residual $68 \%$ variance in hatchling size occurring within or among groups of egg capsules (Fig. 1).

The hatchling size of Cominella maculosa also showed no differences between the 2 locations $\left(F_{1,2}=\right.$ 5.564, $\mathrm{p}=0.142$ ), with similar SL obtained from the Harbour and South Coast $(1.60 \pm 0.2 \mathrm{~mm}$ vs. $1.42 \pm$ $0.14 \mathrm{~mm}$, respectively). Similar to C. virgata, $16 \%$ of the variance in hatchling size occurred among sites, with the residual variance $(84 \%)$ occurring within or among groups of egg capsules (Fig. 1). 


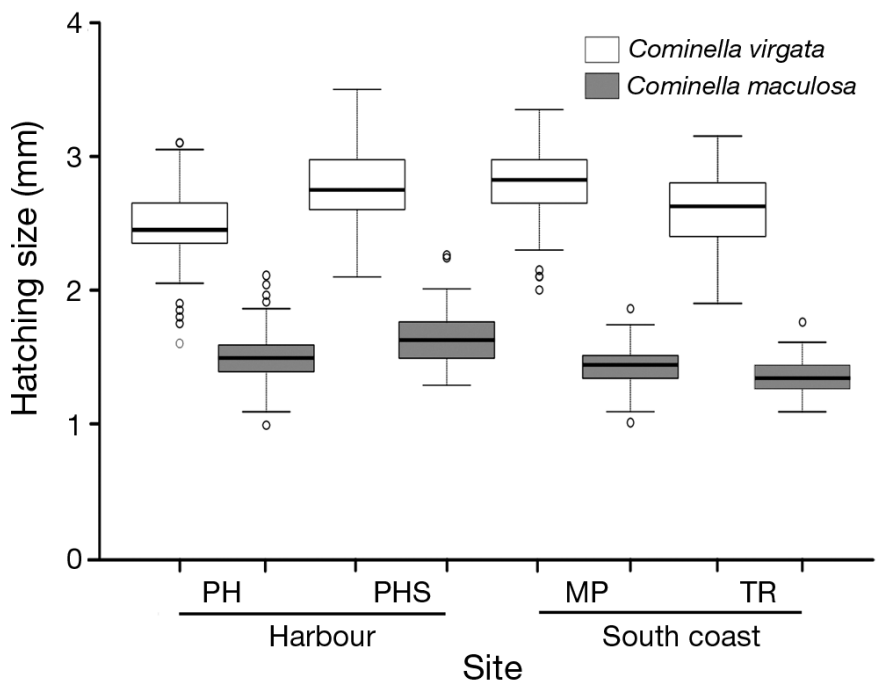

Fig. 1. Cominella virgata and C. maculosa. Variation in hatchling size from 2 locations in the Wellington region, New Zealand. PH: Point Howard, PHS: Point Halswell, MP: Moa Point, TR: Te Raekaihau Point. Central line in each box $=$ median, upper and lower edges of the box $=75$ th and 25 th percentiles. Whiskers $=$ range without outliers, circles $=$ outliers

Subsequent 1-way ANOVA revealed that hatchling size significantly varied among sites for both species (C. virgata: $F_{3,396}=34.419, \mathrm{p}<0.0001$; C. maculosa: $\left.F_{3,396}=51.892, \mathrm{p}<0.0001\right)$. For $C$. virgata, hatchlings from the southern coast site MP and the Harbour site PHS were significantly larger than those from TR, and hatchlings from the Harbour site PH were smallest (post hoc Tukey tests, $\mathrm{p}<0.05$ ). For C. maculosa, hatchling size was significantly different among all sites, with $\mathrm{PHS}>\mathrm{PH}>\mathrm{MP}>\mathrm{TR}$.

Because for both species the variability in hatchling size was not significant between locations but did vary by sites, only those differences were further evaluated in the manipulative experiments. Locations (i.e. Harbour and South Coast) were removed from the models in the following performance analyses.

\section{Size-dependent performance of juveniles in desiccation conditions}

Cominella virgata hatchlings grew in control and desiccation treatments over $8 \mathrm{wk}$ from an initial SL of $2.62 \pm 0.02 \mathrm{~mm}$ to a final SL of $4.3 \pm 0.07 \mathrm{~mm}$. Growth rates $\left(\mathrm{GR}, \mathrm{mm} \mathrm{d} \mathrm{d}^{-1}\right)$ did not significantly differ between control vs. desiccation treatment: $F_{1,544}=$ $0.11, \mathrm{p}=0.738$; however, there was a significant effect of initial size class $\left(F_{1,544}=10.87, \mathrm{p}=0.001\right)$, with large hatchlings growing at a faster rate than small conspecifics (Fig. 2a,b). The 4 sites also showed significant differences in $\operatorname{GR}\left(F_{3,544}=4.13, \mathrm{p}=0.006\right)$; hatchlings from $\mathrm{PH}$ grew faster than those from PHS and TR (post hoc Tukey tests, $p=0.047$ and $p=0.004$, respectively; Fig. 2a,b). There were no significant interactive effects between the factors ( $p>0.05$ for all interactions).

Cominella maculosa hatchlings in control and desiccation treatments grew over $5 \mathrm{wk}$ from an initial SL of $1.52 \pm 0.06 \mathrm{~mm}$ to a final SL of $1.81 \pm 0.11 \mathrm{~mm}$. Growth rates were not affected by treatment (i.e. control and desiccation: $F_{1,248}=0.11, \mathrm{p}=0.74$ ) or site $\left(F_{3,248}=1.78, \mathrm{p}=0.15\right.$; Fig. $\left.2 \mathrm{c}, \mathrm{d}\right)$; however, the 2 size classes showed significant differences in $\operatorname{GR}\left(F_{1,248}=\right.$ 6.57, $\mathrm{p}=0.01$ ), with large hatchlings growing faster than small ones (Fig. 2c,d).

Hatchling survival of Cominella virgata decreased through $8 \mathrm{wk}$ to a final value of $61 \pm 3.4 \%$ (mean \pm $\mathrm{SE})$. The desiccation treatment did not have a significant effect $(\mathrm{z}=-0.188, \mathrm{p}=0.85)$, nor did hatchling size class $(z=0.54, p=0.59)$. For each site, the survival of large individuals exposed to the desiccation treatment did not differ significantly from those in the control (PH: $\mathrm{z}=-0.35, \mathrm{p}=0.71$; PHS: $\mathrm{z}=-0.44$, $\mathrm{p}=0.66$; MP: $\mathrm{z}=-0.47, \mathrm{p}=0.63$; TR: $\mathrm{z}=-0.98, \mathrm{p}=$ 0.31; Fig. 3a). Similarly, the survival of small individuals from each site did not differ between the desiccation treatment and control $(\mathrm{PH}: \mathrm{z}=-1.45, \mathrm{p}=0.13$; PHS: $\mathrm{z}=-0.35, \mathrm{p}=0.71$; MP: $\mathrm{z}=-0.87, \mathrm{p}=0.38$; TR: $\mathrm{z}=-0.75, \mathrm{p}=0.45$; Fig. 3b). Survival of $C$. virgata from different sites was similar. Relative to $\mathrm{MP}$, hatchling survival was similar among the other 3 study sites: TR $(\mathrm{z}=-0.14, \mathrm{p}=0.89)$, PHS $(\mathrm{z}=-0.27$, $p=0.78)$, and $\mathrm{PH}(\mathrm{z}=0.16, \mathrm{p}=0.87)$. There were no significant interactive effects among the factors included in the analysis ( $p>0.05$ for all interactions; Fig. 3).

Hatchling survival of Cominella maculosa decreased throughout $5 \mathrm{wk}$ to a final value of $8.5 \pm 1.5 \%$ $($ mean $\pm \mathrm{SE})$. For each site, the survival of large individuals did not differ between the control or desiccation treatments $(\mathrm{PH}: \mathrm{z}=-1.18, \mathrm{p}=0.235$; $\mathrm{PHS}: \mathrm{z}=$ 1.37, $\mathrm{p}=0.19$; MP: $\mathrm{z}=-0.86, \mathrm{p}=0.38$; TR: $\mathrm{z}=-0.31$, $\mathrm{p}=0.75$; Fig. 4a). Similarly, the survival of small C. maculosa did not differ between treatments $(\mathrm{PH}$ : $\mathrm{z}=0.31, \mathrm{p}=0.75$; PHS: $\mathrm{z}=0.01, \mathrm{p}=1$; MP: $\mathrm{z}=-0.01$, $\mathrm{p}=1$; TR: $\mathrm{z}=-0.55, \mathrm{p}=0.57$; Fig. 4b). However, we detected significant differences between size classes $(\mathrm{z}=2.98, \mathrm{p}=0.0029)$ : large hatchlings had higher survival than small ones (Fig. 4). Hatchling survival from different sites was also significantly different. Relative to MP, the survival of C. maculosa was lower from TR $(\mathrm{z}=2.97, \mathrm{p}<0.003)$ and PHS $(\mathrm{z}=2.66, \mathrm{p}=$ 

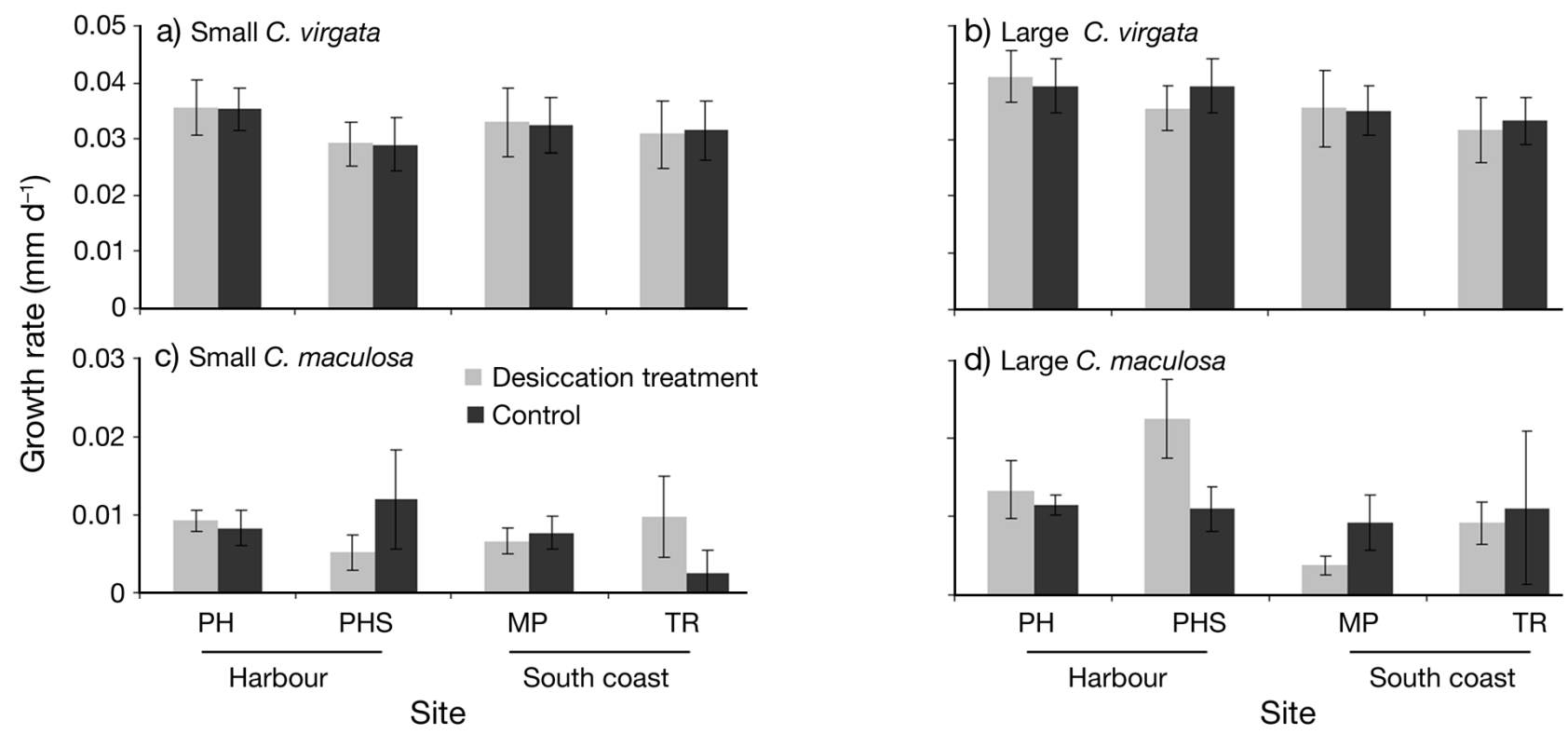

Fig. 2. Cominella virgata and C. maculosa. Growth rates ( $\pm 1 \mathrm{SE})$ of fed hatchlings of $(\mathrm{a}, \mathrm{b})$ C. virgata and (c,d) C. maculosa. See Fig. 1 for site abbreviations

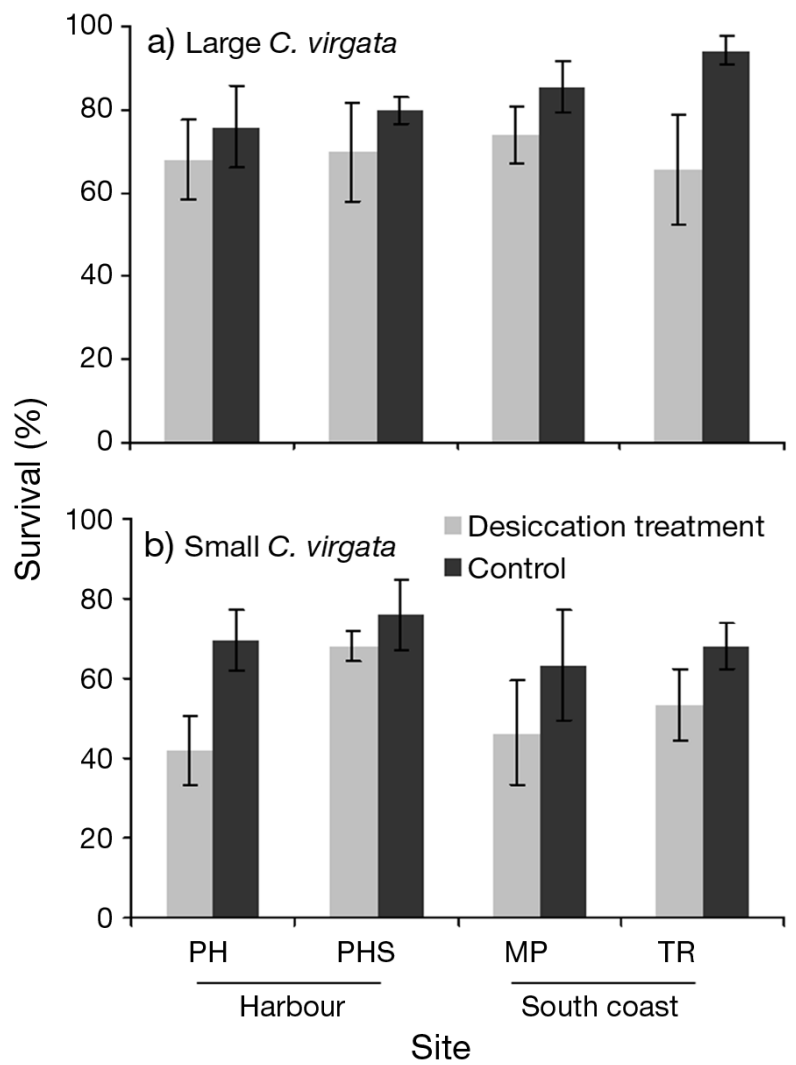

Fig. 3. Cominella virgata. Survival ( $\pm 1 \mathrm{SE}$ ) of fed hatchlings from 2 initial size classes, (a) large and (b) small. See Fig. 1 for site abbreviations

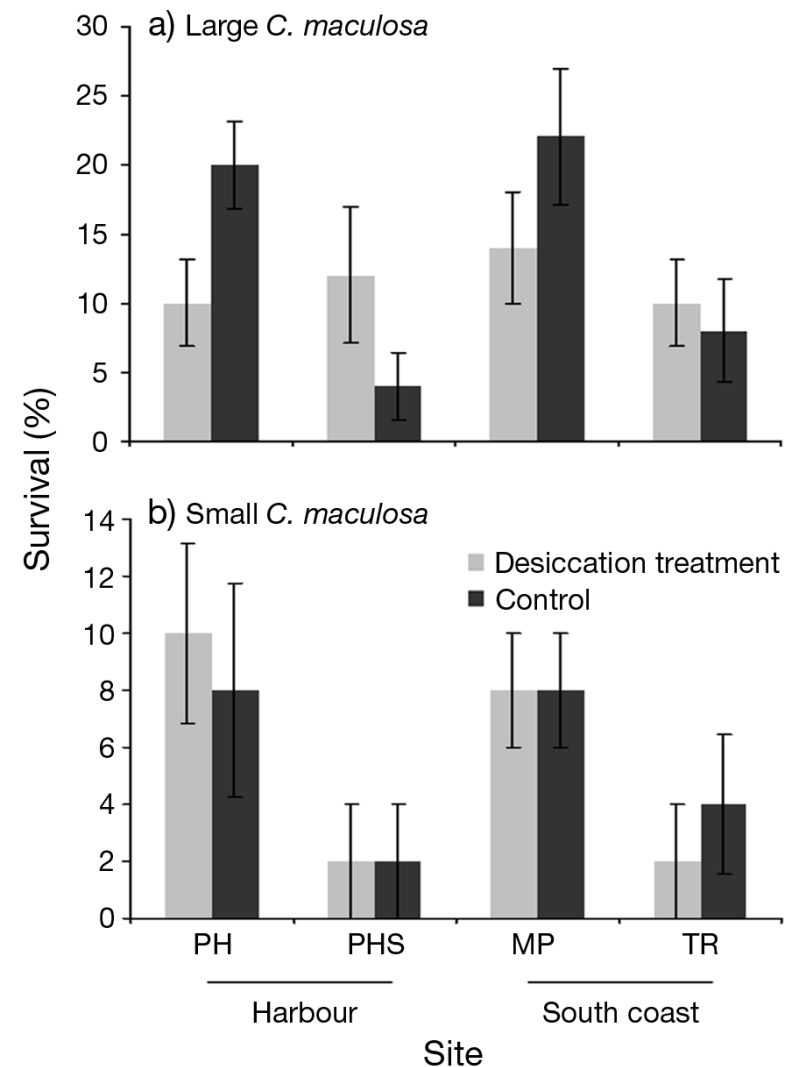

Fig. 4. Cominella maculosa. Survival ( $\pm 1 \mathrm{SE}$ ) of fed hatchlings from 2 initial size classes, (a) large and (b) small. See Fig. 1 for site abbreviations 
0.008) but was similar to that at $\mathrm{PH}(\mathrm{z}=-0.036, \mathrm{p}=$ 0.97). There were no significant interactive effects among the factors included in the analysis $(p>0.05$ for all interactions; Fig. 4).

\section{Size-dependent performance of juveniles in starvation conditions}

Under starvation, SL (mean $\pm \mathrm{SE}$ ) of Cominella virgata hatchlings increased from $2.60 \pm 0.05 \mathrm{~mm}$ to $2.91 \pm 0.05 \mathrm{~mm}$ over the $6 \mathrm{wk}$ experiment, which contrasted with the size attained by snails with a constant food supply over $6 \mathrm{wk}(3.6 \pm 0.06 \mathrm{~mm}$ in Week 6 of Expt 1). The 2 size classes showed significant differences in $\operatorname{GR}\left(F_{1,112}=4.93, \mathrm{p}=0.028\right)$, but in contrast to the desiccation experiment, small hatchlings grew faster than large conspecifics (Fig. 5a). Once again, there were significant differences among sites in $\operatorname{GR}\left(F_{3,112}=3.84, \mathrm{p}=0.011\right)$, with higher GR from MP compared with PHS and TR (post hoc Tukey tests, $p=0.015$ and $p=0.003$, respectively). No interactive effects were observed between site and size (p > 0.05; Fig. 5a).

Cominella maculosa hatchlings held in starvation increased from an initial SL of $1.52 \pm 0.06 \mathrm{~mm}$ to a final SL of $1.61 \pm 0.06 \mathrm{~mm}$ during the $3 \mathrm{wk}$ experiment. This was similar to the size attained by peers with a constant food supply over 3 wk (1.65 \pm $0.06 \mathrm{~mm}$ in Week 3 of Expt 1). There were significant interactive effects between sites and hatchling size class $\left(F_{3,80}=3.45, \mathrm{p}=0.02\right)$, with large hatchlings from MP growing at a lower rate than large individuals from TR and small ones from $\mathrm{PH}, \mathrm{PHS}$, and MP (post hoc Tukey tests, p < 0.018 in all cases; Fig. 5b).

The survival of starved Cominella virgata hatchlings decreased $45 \%$ compared to that of fed hatchlings over the same $6 \mathrm{wk}$ period. Relative to control conditions, the survival of large and small $C$. virgata from one of the sites (PHS) under starvation was not different (small: $\mathrm{z}=0.87, \mathrm{p}=0.38$; large: $\mathrm{z}=-1.35, \mathrm{p}=$ 0.174). However, the survival of large individuals under starvation was significantly reduced compared to hatchlings in control conditions for the other 3 sites (PH: $\mathrm{z}=2.37, \mathrm{p}=0.017 ; \mathrm{MP}: \mathrm{z}=2.04, \mathrm{p}=0.04 ; \mathrm{TR}: \mathrm{z}=$ 2.61, $p=0.009$; Fig. 6a). Similarly, the survival of small $C$. virgata under starvation was significantly lower relative to control conditions at these sites $(\mathrm{PH}$ : $\mathrm{z}=4.76, \mathrm{p}=0.006 ; \mathrm{MP}: \mathrm{z}=1.95, \mathrm{p}=0.05 ; \mathrm{TR}: \mathrm{z}=2.57$, $\mathrm{p}=0.01$; Fig. 6b). The survival of starved individuals did not change among sites or between large and small individuals $(\mathrm{z}=-0.045, \mathrm{p}=0.96)$. No interactive

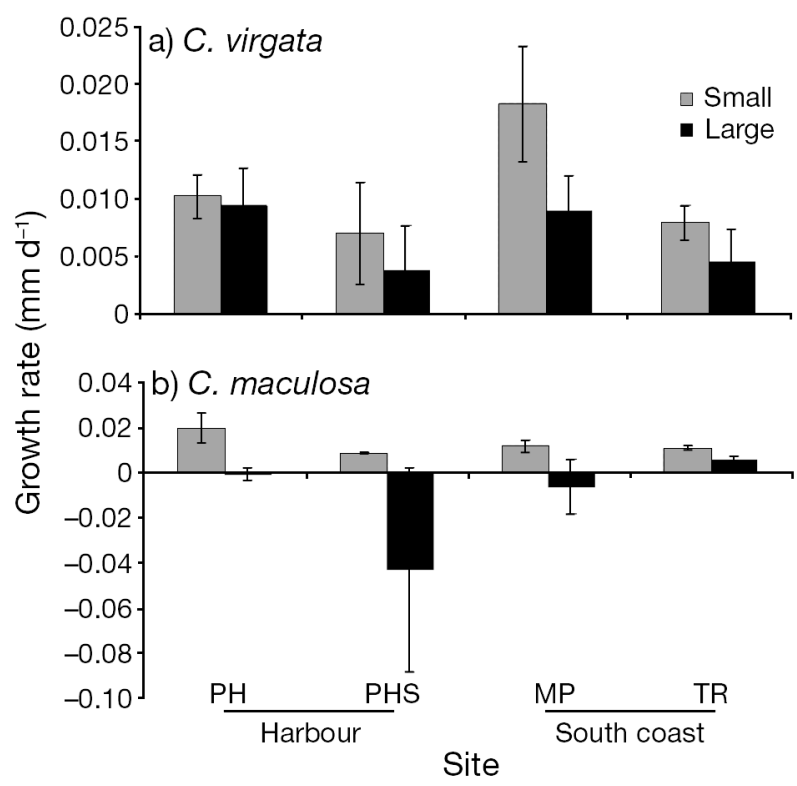

Fig. 5. Cominella virgata and C. maculosa. Growth rates ( $\pm 1 \mathrm{SE}$ ) of starved hatchlings, (a) C. virgata and (b) C. maculosa; see Fig. 1 for site abbreviations. Light-grey bars: desiccation treatment, dark-grey bars: control

effects were observed between the factors $(p>0.05$; Fig. 6).

In contrast, the survival of Cominella maculosa hatchlings under starvation was $26 \%$ higher compared to that of the snails in control conditions after the first $3 \mathrm{wk}$. Relative to starvation, survival was significantly different only for hatchlings from TR, where it was lower in control for both large and small size classes (large: $\mathrm{z}=-2.33, \mathrm{p}=0.01$; small: $\mathrm{z}=$ $-2.05, p=0.04$; Fig. 7). There were no differences in survival between small and large size classes under starvation $(\mathrm{z}=0.83, \mathrm{p}=0.40)$. Relative to $\mathrm{MP}$, the survival of juveniles did not vary among the other 3 study sites: TR $(\mathrm{z}=0.33, \mathrm{p}=0.74)$, PHS $(\mathrm{z}=1.53, \mathrm{p}=$ $0.13)$, and $\mathrm{PH}(\mathrm{z}=1.59, \mathrm{p}=0.11)$. No interactive effects were observed between the factors $(p>0.05$; Fig. 7).

\section{DISCUSSION}

\section{Hatchling size}

In both species of whelks, hatchling size was variable, and the most important source of variation was at the smallest scale explicitly identified, among sites, with substantial variation also occurring within and among females. Contrary to our expectations, and despite the large differences in conditions and 


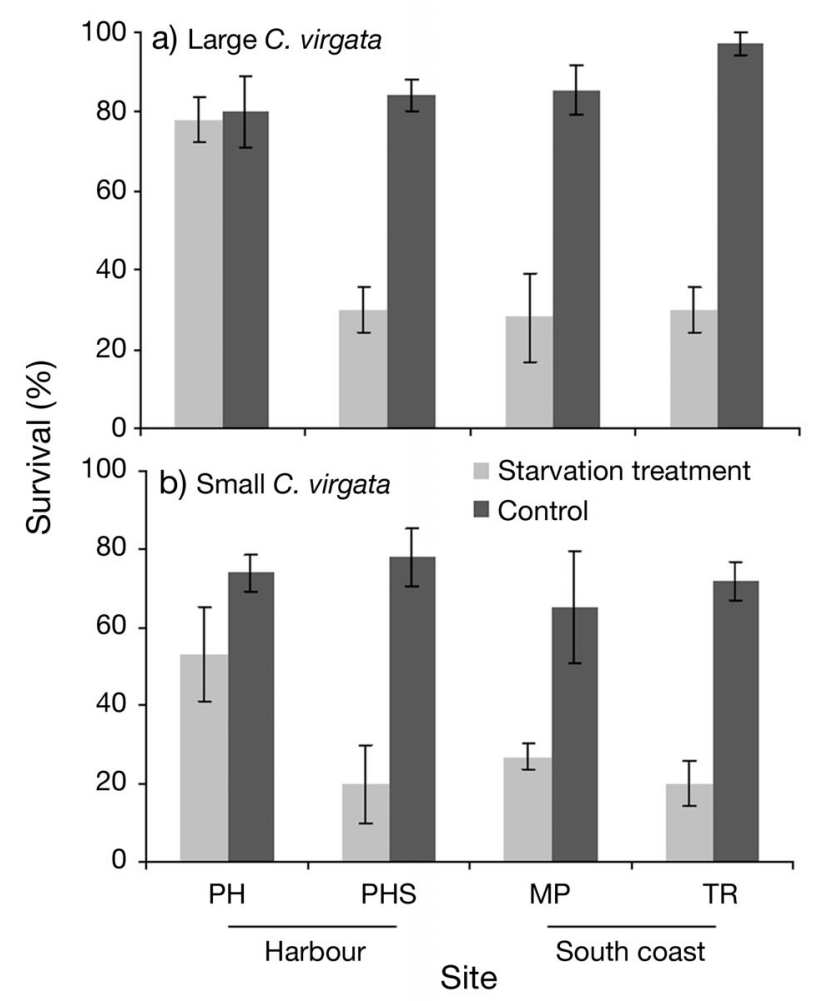

Fig. 6. Cominella virgata. Survival $( \pm \mathrm{SE})$ of starved hatchlings from 2 initial size classes, (a) large and (b) small. See Fig. 1 for site abbreviations

available resources between Harbour and South Coast, the 2 locations did not influence the hatchling size of either species. As in other taxonomic groups, offspring size variation can be dramatically affected by different maternal environments; nonetheless, this trait is also dependent upon the level of observation. At a population level, offspring size can vary considerably within and among individual females (Bernardo 1996). However, among populations, environmental factors appear to play a greater role in determining offspring size, and the overall quality of the habitat into which offspring emerge may act as a selective force on offspring size (e.g. Johnston \& Leggett 2002, Gosselin \& Rehak 2007, Shima \& Swearer 2009).

Studies spanning the last 12 yr have demonstrated that dramatic differences can be observed between both of the locations examined, with Wellington Harbour having greater densities and recruitment rates of invertebrates and fish (Phillips \& Hutchison 2008, Shima \& Swearer 2009, Demello \& Phillips 2011), higher stocks of phytoplankton and particulate concentration (Gardner 2000, Helson et al. 2007), higher quality and faster growing larval fish (Shima \& Swearer 2009, 2010, Swearer \& Shima 2010), and

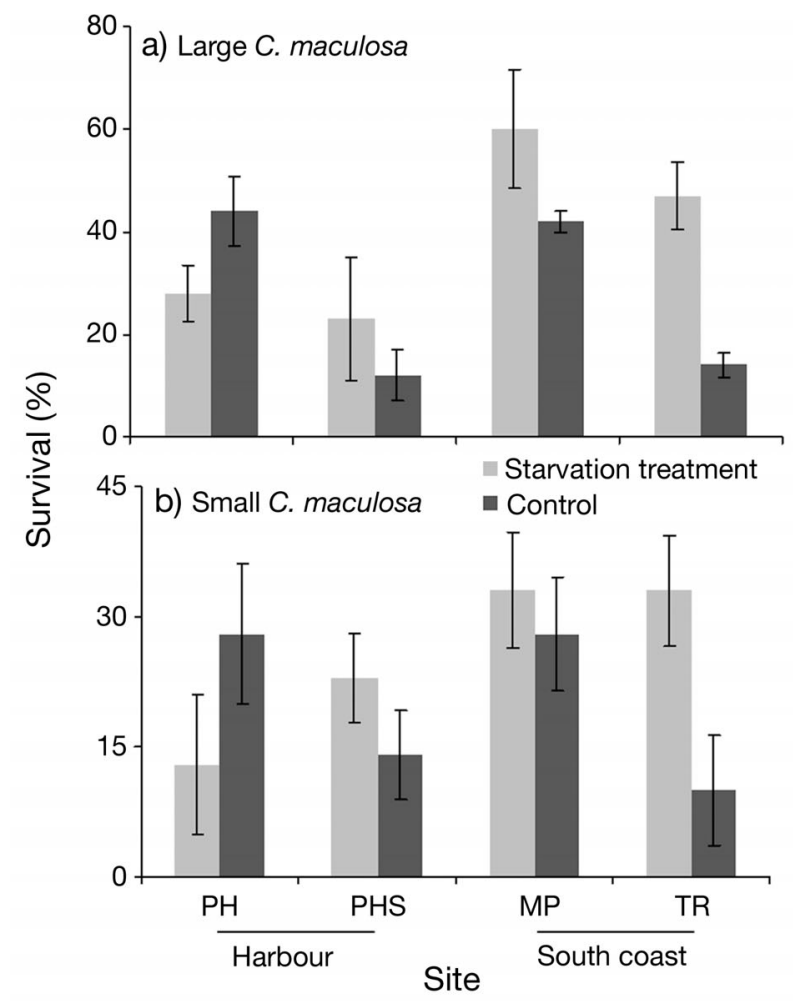

Fig. 7. Cominella maculosa. Survival $( \pm \mathrm{SE})$ of starved hatchlings from 2 initial size classes, (a) large and (b) small. See Fig. 1 for site abbreviations

higher whelk growth rates (N. Phillips unpubl. data), all suggesting a more productive environment in Wellington Harbour. Nonetheless, our study of hatchling whelks suggests that at least for these 2 direct-developing species, smaller scale site-to-site and individual female attributes are more important than these larger-scale differences between locations in mediating offspring traits, contrary to what has been found in species with planktonic larvae in this system (Shima \& Swearer 2009, 2010, Swearer \& Shima 2010).

\section{Size-dependent performance of juveniles under desiccation}

When the performance of Cominella virgata and C. maculosa hatchlings from different maternal habitats were compared in equivalent laboratory conditions (i.e. food ad libitum, control, and desiccation treatments), we observed that the variation in the initial size of hatchlings among the 4 sites was not reflected in hatchling growth rates or survival, suggesting that the factors mediating hatchling size are not necessarily consistent with those acting on hatch- 
ling performance. Further, there was no effect of the desiccation treatment. It is possible that the level of stress caused by this treatment was relatively benign compared to desiccation conditions in the field, although observations suggest that hatchlings and juveniles are rarely found above the sublittoral fringe or in habitats where they are likely to endure considerable aerial exposure at low tide. Perhaps more than desiccation itself, air temperature is a more important stressor for hatchlings at low tide. For example, Moran \& Emlet (2001) found that sun exposure affected hatchling survival in intertidal Nucella ostrina and further that large hatchlings had higher survival in the shaded (i.e. less severe) environment than smaller hatchlings, with no size advantage in the sun-exposed environment.

In contrast, when large and small hatchlings were compared within each site, the expected response was observed, and in both species, large individuals performed better than small conspecifics based on growth rates and survival (the latter only for Cominella maculosa). Although few studies have examined the relationship between maternal environments, offspring size, and offspring performance in marine snails, some of the few published data describe similar responses. Nucella ostrina hatchling size can be influenced by environmental factors, such as exposure to wave action, resulting in smaller sizes from less wave-exposed sites (Gosselin \& Rehak 2007); whereas Moran \& Emlet (2001) reported a size-dependent relationship in the survival and growth of juvenile $N$. ostrina outplanted in the field ( 20 d), with large hatchlings showing higher overall recovery and growth rates than small siblings. Further, in a comparative study among prosobranch gastropods, Spight (1976) suggested that large hatchlings will have higher survivorship than small ones because they can tolerate better physical stress (e.g. dehydration), are susceptible to fewer predators, can travel further to find food or shelter, and have a larger food supply (i.e. larger prey can be taken), although maternal environments were not explicitly examined in that study.

Although we cannot directly compare our results for Cominella virgata and C. maculosa because the experiments were conducted in different years, it is interesting to note that the larger $C$. virgata hatchlings performed better than the smaller C. maculosa hatchlings, with at least $\sim 3$-fold faster growth rates and $\sim 7$-fold higher survival. Similar levels of mortality in a laboratory setting were also recorded by van der Sman (2007) for hatchlings of both species, suggesting that regardless of the sampling years and maternal habitats, the small size of C. maculosa hatchlings could result in an increased vulnerability, especially during the first $2 \mathrm{wk}$ of the crawl-away dispersal period. This higher mortality however, could be balanced by the higher fecundity of $C$. maculosa, which can encapsulate an average of 8-fold greater number of hatchlings per capsule compared with the single embryo per capsule produced by $C$. virgata.

\section{Size-dependent performance of juveniles under starvation}

Not unexpectedly, starved hatchlings of both species performed more poorly than fully-fed conspecifics, attaining smaller shell lengths, slower growth rates, and lower survival (except for starved Cominella maculosa compared with fed peers from 1 site). Interestingly, different maternal habitats and variation in initial size for both species had no effect in the overall survival of starved hatchlings; however, intraspecific differences in growth rates seem to be highly influenced by those factors individually (e.g. C. virgata) or acting in positive interactions (e.g. C. maculosa).

Although inter-specific comparisons of hatchling traits cannot be directly evaluated, the larger species (Cominella virgata) had overall higher growth and survival when starved than the smaller C. maculosa, which could be a direct consequence of a higher maternal investment in larger individuals, especially in terms of lipid reserves (i.e. phospholipids, cholesterol, aliphatic hydrocarbon, triglycerides, diglycerides, and free fatty acids) that have been recorded in hatchlings of both species (S. Carrasco, M. Sewell \& N. Phillips unpubl. data). It has long been recognized that neutral lipids, particularly triglycerides, are an important energy source that fuels the early larval development of planktotrophic echinoids and the embryogenesis and metamorphosis of mollusks (reviewed by Sewell 2005). The possibility of sizedependent allocation of energy reserves in hatchlings, and consequences for performance, is the subject of ongoing studies.

As in the present experiments, other studies of whelks have also shown that food limitation during early life stages reduces the growth rates and survival of individuals compared with fully-fed conspecifics, e.g. Hemifusus tuba (Morton 1986), Chorus giganteus (Gallardo et al. 2004a), or Cominella virgata (van der Sman et al. 2009). Although we finished the starvation experiments after $6 \mathrm{wk}$ and $3 \mathrm{wk}$ (C. virgata and C. maculosa, respectively) due to the 
low numbers of individuals in some of the replicate containers, the remaining juveniles were kept in the same laboratory conditions and were able to survive unfed for $18 \mathrm{wk}$ (C. virgata) and $8 \mathrm{wk}$ (C. maculosa). These observations demonstrate the potential for hatchling whelks to withstand prolonged periods without food, although there is the possibility that these species (as many marine invertebrate species) may take up dissolved organic matter (DOM), which can be particularly important for juveniles (Morton 1986).

Overall, examining the performance of newly hatched direct-developing snails under different conditions allows us to understand the importance of considering different scales of variation when the size-performance relationship is evaluated. Because different scales may evaluate completely different contexts in the life history of a species (Marshall \& Uller 2007), maternal and offspring characteristics should ideally both be considered. Variation at the site level was important for both the size and performance of hatchlings, particularly growth rates; however, these responses were not necessarily consistent among sites, and sometimes hatchling size interacted with sites, resulting in complex patterns. Further, size may be important in mediating performance in response to some stressors, but not others, or to multiple stressors in different ways. Thus, the causes and consequences of offspring size variation can be complex, even for direct-developing whelks that develop and hatch in the same environment as their mothers. Further studies should evaluate the mechanisms underlying the variable performance exhibited by juveniles and how it may be related to maternal history or environmental conditions.

Acknowledgements. This research was funded by a CONICYT-VUW PhD scholarship to S.C. A.P.M. acknowledges funding support from MECESUP-UV 0604. The authors thank the National Institute of Water and Atmospheric Research, Greta Point, Wellington, for the facilities provided during initial sampling and experiments. S. Geange and 3 anonymous reviewers provided useful comments on earlier versions of the manuscript.

\section{LITERATURE CITED}

Allen RM, Buckley YM, Marshall DJ (2008) Offspring size plasticity in response to intraspecific competition: an adaptative maternal effect across life-history stages. Am Nat 171:225-237

Bernardo J (1996) The particular maternal effect of propagule size, especially egg size: patterns, models, quality of evidence and interpretations. Am Zool 36:216-236

Clark KE, Hartley SE, Johnson SN (2011) Does mother know best? The preference-performance hypothesis and parent-offspring conflict in aboveground-belowground herbivore life cycles. Ecol Entomol 36:117-124

Crawley MJ (2007) The R book. John Wiley \& Sons, Chichester

$>$ Crean AJ, Marshall DJ (2009) Coping with environmental uncertainty: dynamic bet hedging as a maternal effect. Philos Trans R Soc Lond B 364:1087-1096

- Demello R, Phillips NE (2011) Variation in mussel and barnacle recruitment parallels a shift in intertidal community structure in the Cook Strait region of New Zealand. Mar Freshw Res 62:1221-1229

> Du WG (2006) Phenotypic plasticity in reproductive traits induced by food availability in a lacertid lizard, Takydromus septentrionalis. Oikos 112:363-369

> Fisher R, Sogard SM, Berkeley SA (2007) Trade-offs between size and energy reserves reflect alternative strategies for optimizing larval survival potential in rockfish. Mar Ecol Prog Ser 344:257-270

Fox CW (2000) Natural selection on seed-beetle egg size in nature and the laboratory: variation among environments. Ecology 81:3029-3035

> Gallardo CS, Díaz MA, Varela C (2004a) Growth and survival of early juvenile trumulco snail Chorus giganteus (Gastropoda: Muricidae) fed two prey species. NZ J Mar Freshw Res 38:767-773

Gallardo CS, Manque C, Filún M (2004b) Comparative resistance to starvation among early juveniles of some marine muricoidean snails. Nautilus 118:121-126

Gardner JPA (2000) Where are the mussels on Cook Strait (New Zealand) shores? Low seston quality as a possible factor limiting multispecies distributions. Mar Ecol Prog Ser 194:123-132

> Gosselin LA (1997) An ecological transition during juvenile life in a marine snail. Mar Ecol Prog Ser 157:185-194

> Gosselin LA, Chia FS (1995a) Characterizing temperate rocky shores from the perspective of an early juvenile snail: the main threats to survival of newly hatched Nucela emarginata. Mar Biol 122:625-635

Gosselin LA, Chia FS (1995b) Distribution and dispersal of early juvenile snails: effectiveness of intertidal microhabitats as refuges and food sources. Mar Ecol Prog Ser 128:213-223

> Gosselin LA, Rehak R (2007) Initial juvenile size and environmental severity: influence of predation and wave exposure on hatchling size in Nucella ostrina. Mar Ecol Prog Ser 339:143-155

> Green BS, McCormick MI (2005) Maternal and paternal effects determine size, growth and performance in larvae of a tropical reef fish. Mar Ecol Prog Ser 289:263-272

> Helmuth B, Harley CDG, Halpin PM, O'Donnell M, Hofmann GE, Blanchette CA (2002) Climate change and latitudinal patterns of intertidal thermal stress. Science 298:1015-1017

Helson JG, Pledger S, Gardner JPA (2007) Does differential particulate food supply explain the presence of mussels in Wellington Harbour (New Zealand) and their absence on neighboring Cook Strait shores? Estuar Coast Shelf Sci 72:223-234

Johnston TA, Leggett WC (2002) Maternal and environmental gradients in the egg size of an iteroparous fish. Ecology 83:1777-1791

Kamel SJ, Oyarzun FX, Grosberg RK (2010) Reproductive biology, family conflict, and size of offspring in marine invertebrates. Integr Comp Biol 50:619-629

Krist M (2011) Egg size and offspring quality: a meta- 
analysis in birds. Biol Rev Camb Philos Soc 86:692-716

Lloyd MJ, Gosselin LA (2007) Role of maternal provisioning in controlling interpopulation variation in hatching size in the marine snail Nucella ostrina. Biol Bull 213: 316-324

Marshall DJ, Keough MJ (2004) Variable effects of larval size on post-metamorphic performance in the field. Mar Ecol Prog Ser 279:73-80

Marshall DJ, Keough MJ (2008) The evolutionary ecology of offspring size in marine invertebrates. Adv Mar Biol 53: 1-60

Marshall DJ, Keough MJ (2009) Does interspecific competition affect offspring provisioning? Ecology 90:487-495

Marshall DJ, Uller T (2007) When is a maternal effect adaptative? Oikos 116:1957-1963

Marshall DJ, Bolton TF, Keough MJ (2003) Offspring size affects the post-metamorphic performance of a colonial marine invertebrate. Ecology 84:3131-3137

Marshall DJ, Cook CN, Emlet RB (2006) Offspring size effects mediate competitive interactions in a colonial marine invertebrate. Ecology 87:214-225

Moran AL, Emlet RB (2001) Offspring size and performance in variable environments: field studies on a marine snail. Ecology 82:1597-1612

Moran AL, Manahan DT (2004) Physiological recovery from prolonged 'starvation' in larvae of the Pacific oyster Crassostrea gigas. J Exp Mar Biol Ecol 306:17-36

Morton B (1986) Reproduction, juvenile growth, consumption and the effects of starvation upon the South China Sea whelk Hemifusus tuba (Gmelin) (Prosobranchia: Melongenidae). J Exp Mar Biol Ecol 102:257-280

Morton J, Miller M (1968) The New Zealand sea shore. C. Tinling, Liverpool

Phillips NE (2002) Effect of nutrition-mediated larval condition on juvenile performance in a marine mussel. Ecology 83:2562-2574

Phillips NE, Hutchison E (2008) Grazer effects on algal assemblages and mussel recruitment in two different mid intertidal communities in the Cook Strait, New Zealand. NZ J Mar Freshw Res 42:297-306

Editorial responsibility: Pei-Yuan Qian, Kowloon, Hong Kong SAR
R Development Core Team (2010) R: a language and environment for statistical computing. The R Foundation for Statistical Computing, Vienna. Available at www.Rproject.org

$>$ Rivest B (1983) Development and the influence of nurse egg allotment on hatching size in Searlesia dira (Reeve, 1846) (Prosobranchia: Buccinidae). J Exp Mar Biol Ecol 69: 217-241

Sewell MA (2005) Utilization of lipids during early development of the sea urchin Evechinus chloroticus. Mar Ecol Prog Ser 304:133-142

Shima JS, Swearer SE (2009) Spatially variable larval histories may shape recruitment rates of a temperate reef fish. Mar Ecol Prog Ser 394:223-229

> Shima JS, Swearer SE (2010) The legacy of dispersal: larval experience shapes persistence later in the life of a reef fish. J Anim Ecol 79:1308-1314

Spight TM (1976) Ecology of hatchling size for marine snails. Oecologia 24:283-294

> Swearer SE, Shima JS (2010) Regional variation in larval retention and dispersal drives recruitment patterns in a temperate reef fish. Mar Ecol Prog Ser 417:229-236

> Thiyagarajan V, Harder T, Qiu JW, Qian PY (2003) Energy content at metamorphosis and growth rate of the early juvenile barnacle Balanus amphitrite. Mar Biol 143: 543-554

> Tsai ML, Dai CF (2001) Life history plasticity and reproductive strategy enabling the invasion of Ligia exotica from the litoral zone to an inland creek. Mar Ecol Prog Ser 210:175-184

van der Sman J (2007) Reproductive allocation and maternal investment in whelks. Master's thesis, Victoria University of Wellington

van der Sman J, Phillips NE, Pfister CA (2009) Relative effects of maternal and juvenile food availability for a marine snail. Ecology 90:3119-3125

Walker SE, Rypstra AL, Marshall SD (2003) The relationship between offspring size and performance in the wolf spider Hogna helluo (Aranae: Lycosidae). Evol Ecol Res 5:19-28

Submitted: September 16, 2011; Accepted: April 16, 2012 Proofs received from author(s): July 7, 2012 